\title{
Ultimate Load Capacity of Optimal Designed Angelina" Beams
}

\author{
Ferhat Erdal*1 Osman Tunca ${ }^{2}$, Serkan Tas ${ }^{3}$, Serdar Carbas ${ }^{4}$ \\ ${ }^{1}$ Corresponding Autor: Akdeniz University, Department of Civil Engineering-Antalya-TURKEY \\ ${ }^{2,4}$ Karamanoglu Mehmetbey University, Department of Civil Engineering -Karaman-TURKEY \\ ${ }^{3}$ Akdeniz University, Department of Civil Engineering -Antalya-TURKEY
}

\begin{abstract}
This study briefly summarizes the results of experimental tests performed on optimal designed Angelina ${ }^{\mathrm{TM}}$ steel beams. The objective of the investigation was to study the effect of hole geometry on the mode of failure and ultimate strength of such beams under loading conditions. For this purpose, six optimal designed angelina beams are tested in a self reacting frame to determine the ultimate load carrying capacities of these new generation web-expanded beams. The specimens were all fabricated from IPN beams and were expanded to almost 1.5 times the original depth. All specimens were fabricated from ASTM A-36 steel. The design methods for the specimens will be the harmony search algorithm and particle swarm method which are stochastic search techniques. The minimum weight is taken as the design objective while the design constraints are implemented from the SCI (Steel Construction Institute). Design constraints include the displacement limitations, overall beam flexural capacity, beam shear capacity, overall beam buckling strength, web post flexure and buckling, vierendeel bending of upper and lower tees and local buckling of compression flange. The design methods adopted in this publication are consistent with BS5950.
\end{abstract}

Keywords: Web-expanded steel beams; stochastic search methods; harmony search; particle swarm; load sarrying capacity; structural optimization.

\section{Introduction}

Optimization, also known as mathematical programming, is the collection of mathematical principles and methods used for solving design problems in many disciplines, including engineering field. The subject grew from a realization that design problems in manifestly engineering disciplines have important mathematical elements in common. Because of this commonality, many engineering problems can be formulated and solved by using the unified set of ideas and methods that make up the field of structural optimization. Especially in steel industrial, it is possible to design the steel structures by selecting from the current profile lists with the lowest weight and with low cost via structural optimization used the stochastic methods ${ }^{[1-5]}$. In this study, Angelina ${ }^{\text {"w }}$ steel beams are designed to be most economical with structural optimization methods, calculation of the load carrying capacities of these beams, and as a result, it is aimed to spread the usage in engineering applications in our country. In this context, the solution of the discrete variable optimization problem, which is obtained by formulating the optimal sizing problems of the web-expanded steel beams with sinusoid spaces, is derived by using the improved HS (Harmony Search) and PS (Particle Swarm) metahustic optimization techniques $^{[7-8]}$. Details of the NPI profile sections, beam geometry and distance between web spaceses are taken as design

Copyright (C) 2018 Ferhat Erdal et al.

doi: $10.18063 /$ scr.v2i3.571

This is an open-access article distributed under the terms of the Creative Commons Attribution Unported License

(http://creativecommons.org/licenses/by-nc/4.0/), which permits unrestricted use, distribution, and reproduction in any medium, provided the original work is properly cited. 
variables under the optimum design of these beams. The design criteria for these systems are based on the provisions of the BS 5950 specification (British Standard). Web-expanded beams; it is cut by CNC (Computer Numerical Control) method in the form of sinus curve depending on the geometry along the web of the steel I-section profile and is formed as a result of re-joining the obtained parts by welding. As a result of these operations shown in Figure 1, the length of the beam, the cross-sectional coefficient and the moment of inertia increase, while the weight of the beam decreases compared to the initial state.

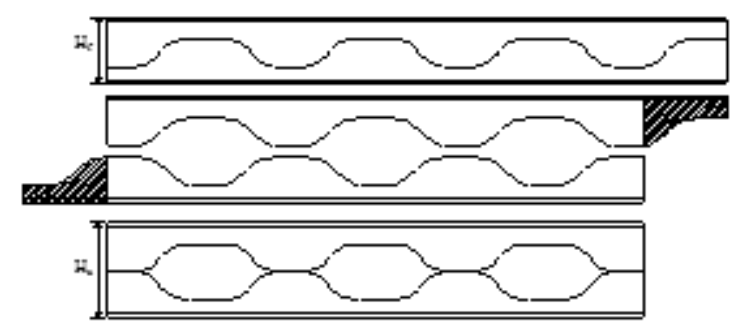

Figure 1. Height enhanging process of the web of Angelina ${ }^{\mathrm{w}}$ steel beams

These beams are preferred with their impressive architectural appearance in long spanned structures such as office buildings, shopping centers, parking lots and sports halls. Increased web-height are also used as roof beams to cover large areas, providing excellent results due to their weight and cost savings as well as visuals. These beams, which are calculated according to the applied load combinations and the opening dimensions, distance between openings, number of openings in the sizing parameters, show approximately $40-60 \%$ higher and $40-60 \%$ more resiliant than the original I-section profile. Floor height constrains on the buildings are one of the important problems. After cutting and re-welding, higher and lighter web allows the electric, water and mechanical installation pipes to pass smoothly through the openings formed in the web region of the raised beams, as shown in Figure 2.

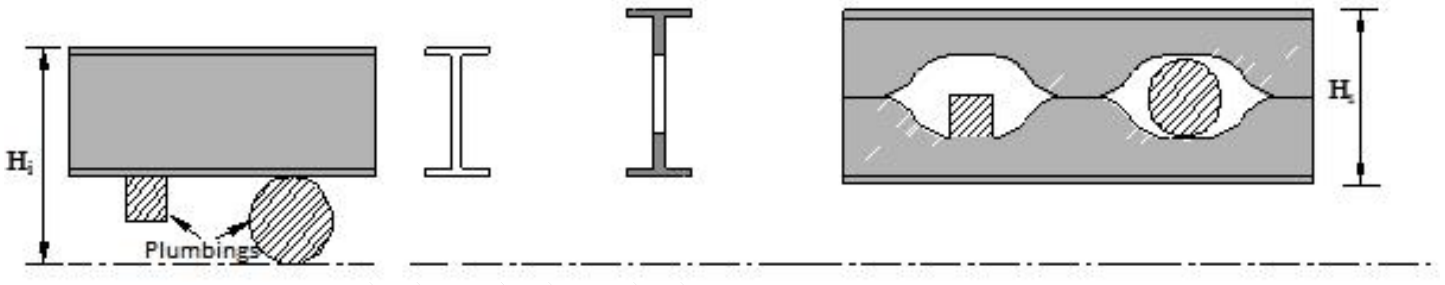

Figure 2. Display of steel beam with web-opening for floor height difference

As a result of the increasing height of the rafters because of welding of the upper and lower parts after cuting out along the web of the standart I-sections, the section modulus and the moment of inertia increase, as shown in Figure. 2.

\section{Used Methods in Beam Optimization}

In this study, two different stochastic optimization methot were used to develop algorithm to optimize geometry of Angelina " steel beams. As a result of these studies, algorithm that has capability of finding optimal dimension of sinusoidal web-expanded beams was prepared by using Harmony Search (HA) and Particle Swarm (PS) methods. This algorithm is compiled in the Windows environment by using the FORTRAN programming language. The analytical and design skills of the optimization algorithms are given below.

The solution can be produced according to British Standard (BS) specifications.

The optimum design can be achieved by considering the following specifications for the steel web-expanded beam (Kerdal and Nethercot 1982, Zaarour and Redwood 1996);

- Bending and axial stress verification

- Beam web-buckling verification

- Maximum displacement verification

- Vierendeel bending verifications

- Slenderness verification 
- Shear stress verification

\subsection{Harmony Search Algorithm}

The Harmony Search (HS) method, which is generated by Geem and Lee, is based on the concept that musical instruments must be tuned to obtain a common harmony before the orchestra begins to play a music composition (Lee and Geem 2004). The adaptation of musical instruments in the play of an orchestra's work is likened to the global optimum of the optimization process. Most structural optimization methods need complex mathematical algorithms that need beginning information, and selection of initial values. These are important to ensure that the algorithm achieves convergence for global optimal value. HS algorithm does not need any complex mathematical algorithms and initial values are not necessary. In HS method, instead of search by increasing the degree, random search is performed. And thus, there is no need for differential information.

I - Initialization of harmony memory matrix: Firstly, harmony memory matrix $(\mathrm{H})$ is generated randomly. This matrix represents a design population for the solution of a problem under consideration and incorporates a specified number of solutions referred to as harmony size $(\mu)$. Each solution vector $\left(\mathrm{I}^{\mathrm{i}}\right)$ consists of $\left(\mathrm{N}_{\mathrm{d}}\right)$ design variables integer number between 1 to $\left(\mathrm{N}_{\mathrm{s}}\right)$ (number of values) selected randomly each of which corresponds sequence number of design variables in the design pool and is represented in a separate row of the matrix. Consequently, the size of $\mathrm{H}$ is $(\mathrm{H}=$ $\mu \times N_{d}$ ). $I_{i}^{i}$ is the sequence number of the $i^{\text {th }}$ design variable in the $\mathrm{j}^{\text {th }}$ randomly selected feasible solution (Equation 1 ).

$\mathrm{H}=\left|\begin{array}{llll}\mathrm{I}_{1}^{2} & \mathrm{I}_{2}^{2} & \cdots & \mathrm{I}_{\mathrm{N}_{\mathrm{d}}}^{2}\end{array}\right| \Phi\left(\mathrm{I}^{2}\right)(1)$

II - Evaluation of harmony memory matrix: After the harmonic memory matrix solutions are analyzed, their objective function values are computed in the combined general formula. The solutions evaluated are sorted in the matrix in the increasing order of objective function values, that is $\Phi\left(\mathrm{I}^{1}\right) \leq \Phi\left(\mathrm{I}^{2}\right) \leq \ldots \leq \Phi\left(\mathrm{I}^{\mu}\right)$.

III - Improvising a new harmony: Upon sampling of a new set of values for parameters, the new solution vector $\mathrm{I}^{\prime}=\left[\mathrm{I}_{1}, \mathrm{I}_{2}^{\prime}, \ldots, \mathrm{I}_{\mathrm{N}_{\lambda}}^{\prime}\right\rceil$ is generated. In the harmony memory consideration, each design variable is selected at random from either $\mathrm{H}$ or the entire discrete set. The probability that a design variable is selected from the harmony memory is controlled by a parameter called harmony memory considering rate (hmcr). To execute this probability, a random number $\left(r_{i}\right)$ is generated between 0 and 1 for each variable $\left(I_{i}\right)$. If $\left(r_{i}\right)$ is smaller than or equal to (hmcr), the variable is chosen from harmony memory in which case it is assigned any value from the $i^{\text {th }}$ column of the $H$, representing the value set of variables in $\mu$ solutions of the matrix (Eq. 2). If $r_{i} \leq \mathrm{hmcr}$, a random value is assigned to the variable from the entire discrete set.

$$
I_{i}^{\prime}=\left\{\begin{array}{c}
I_{i}^{\prime} \in\left\{I_{i}^{1}, I_{i}^{2}, \ldots I_{i}^{\mu}\right\} \text { if } r_{i} \leq \text { hmcr } \\
I_{i}^{\prime} \in\left\{1, \ldots, N_{s}\right\} \text { if } r_{i}>\text { hmcr }
\end{array}\right.
$$

If a design variable attains its value from harmony memory, it is checked whether this value should be pitch-adjusted or not (Equation 3). Pith adjustment simply means sampling the variable's one of the neighboring values, obtained by adding or subtracting one from its current value. Similar to (hmcr) parameter, it is operated with a probability known as pitch adjustment rate (par).

$$
\mathrm{I}_{\mathrm{i}}^{\prime \prime}=\left\{\begin{array}{c}
\mathrm{I}_{\mathrm{i}}^{\mathrm{I}} \pm 1 \text { if } \mathrm{r}_{\mathrm{i}} \leq \text { par } \\
\mathrm{I}_{\mathrm{i}}^{\mathrm{I}} \text { if } \mathrm{r}_{\mathrm{i}}>\text { par }
\end{array}\right.
$$

IV - Updating parameters: After selecting the new values for each design variable the objective function value is calculated for the new harmony vector. If this value is better than the worst harmony vector in the harmony matrix, it is then included in the matrix while the worst one is taken out of the matrix. The harmony memory matrix is then sorted in descending order by considering the objective function value.

V - Termination: Steps III and IV are repeated until the termination criterion which is the preselected maximum number of cycles $\left(\mathrm{N}_{\mathrm{cyc}}\right)$ is reached. This number is selected large enough such that within this number of design cycles no further improvement is observed in the objective function.

\subsection{Particle Swarm Method}


Particle swarm optimizer (PSO) is based on the social behavior of animals such as fish schooling, insect swarming and birds flocking. This behavior is concerned with grouping by social forces that depend on both the memory of each individual as well as the knowledge gained by the swarm ${ }^{[8]}$. The procedure involves a number of particles which represent the swarm being initialized randomly in the search space of an objective function. Each particle in the swarm represents a candidate solution of the optimum design problem. The particles fly through the search space and their positions are updated using the current position, a velocity vector and a time step. The steps of the algorithm are outlined in the following as given in (P.R. Knowles 1985, J.K. Ward 1990) ${ }^{[10-11]}$ :

I - Initializing Particles: A swarm consists of a predefined number of particles referred to as swarm size $(\mu)$. Each particle (P) incorporates two sets of components; a position vector I and a velocity vector V (Equation 13). The position vector I retains the positions of design variables, while the velocity vector $\mathrm{V}$ is used to vary these positions during the search. Each particle in the swarm is constructed by a random initialization such that all initial positions $\mathrm{I}_{\mathrm{i}}^{(0)}$ and velocities $v_{i}^{(0)}$ are assigned from Equations 4-6:

$$
\begin{aligned}
& \mathrm{P}=(\mathrm{I}, \mathrm{v}), \mathrm{I}=\left[\mathrm{I}_{1}, \mathrm{I}_{2}, \ldots, \mathrm{I}_{\mathrm{N}_{\mathrm{d}}}\right], \mathrm{v}=\left[\mathrm{v}_{1}, \mathrm{v}_{2}, \ldots, \mathrm{v}_{\mathrm{N}_{\mathrm{d}}}\right](4) \\
& \mathrm{I}_{\mathrm{i}}^{(0)}=\mathrm{I}_{\min }+\mathrm{r}\left(\mathrm{I}_{\max }-\mathrm{I}_{\min }\right), \mathrm{i}=1, \ldots, \mathrm{N}_{\mathrm{d}}(5) \\
& \mathrm{v}_{\mathrm{i}}^{(0)}=\frac{\mathrm{I}_{\min }+\mathrm{r}\left(\mathrm{I}_{\max }-\mathrm{I}_{\min }\right)}{\Delta \mathrm{t}}, \mathrm{i}=1, \ldots, \mathrm{N}_{\mathrm{d}}(6)
\end{aligned}
$$

Where, $\mathrm{r}$ is a random number sampled between 0 and $1 ; \Delta t$ is the time step; and $I_{\min }$ and $I_{\max }$ are the sequence numbers of the first and last standard steel sections in the profile list, respectively.

II - Evaluating Particles: All the particles are analyzed, and their objective function values are calculated using design space positions.

III - Updating the Particles' Best and the Global Best: A particle's best position (the best design with minimum objective function) thus far is referred to as particle's best and is stored separately for each particle in a vector B. On the other hand, the best feasible position located by any particle since the beginning of the process is called the global best position, and it is stored in a vector G. At the current iteration $\mathrm{k}$, both the particles' bests and the global best are updated (Equation 7).

$$
\mathrm{B}^{(\mathrm{k})}=\left[\mathrm{B}_{1}^{(\mathrm{k})}, \ldots \mathrm{B}_{\mathrm{i}}^{(\mathrm{k})}, \ldots \mathrm{B}_{\mathrm{N}_{\mathrm{d}}}^{(\mathrm{k})}\right], \mathrm{G}^{(\mathrm{k})}=\left[\mathrm{G}_{1}^{(\mathrm{k})}, \ldots \mathrm{G}_{\mathrm{i}}^{(\mathrm{k})}, \ldots \mathrm{G}_{\mathrm{N}_{\mathrm{d}}}^{(\mathrm{k})}\right](7)
$$

IV - Updating a Particle's Velocity Vector: The velocity vector of each particle is updated considering the particle's current position, the particle's best position and global best position, as follows:

$$
v_{i}^{(k+1)}=w v_{i}^{(k)}+c_{1} r_{1}\left(\frac{G_{i}^{(k)}-I_{i}^{(k)}}{\Delta t}\right)+c_{2} r_{2}\left(\frac{B_{i}^{(k)}-I_{i}^{(k)}}{\Delta t}\right)(8)
$$

Where, $r_{1}$ and $r_{2}$ are random numbers between 0 and $1 ; w$ is the inertia of the particle which controls the exploration properties of the algorithm; and $c_{1}$ and $c_{2}$ are the trust parameters, indicating how much confidence the particle has in itself and in the swarm, respectively.

V - Updating a Particle's Position Vector: Next, the position vector of each particle is updated with the updated velocity vector (Equation 9), which is rounded to nearest integer value for discrete variables.

$I_{i}^{(k+1)}=I_{i}^{(k)}+v_{i}^{(k+1)} \Delta t(9)$

VI - Termination: The steps II through $\mathrm{V}$ are repeated in the same way for a predefined number of iterations $N_{i t e}$. 


\section{OPTIMUM DESIGN PROBLEM OF ANGELINA" BEAMS}

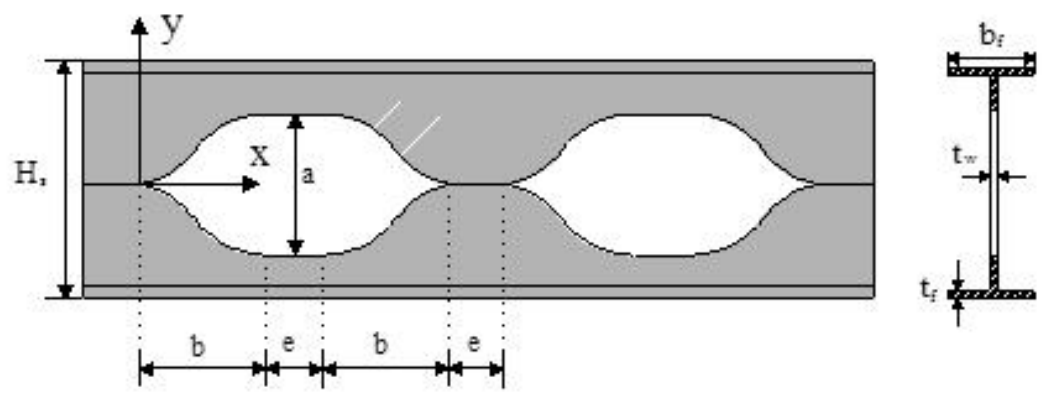

Figure 3. Geometry and notation for Angelina" beam

Geometry and notations in the problem of optimum design of the Angelina" steel beams in the form of a minimum weighted sine-curve are shown in Figure 3. Design parameters are considered as follows:

Set of design parameters: $\{I\}=\left\{I_{1}, I_{2}, I_{3}, I_{4}, I_{5}\right\}^{T}$ (10)

In the defined variable set in Equation $10, I_{1}$ is the sequence number of the steel section profile, $I_{2}$ is the height of the web-opening will be formed in the beam, $I_{3}$ is the horizontal length of each sinusoidal curve will be formed in the beam, $I_{4}$ is the length of the flat portion of the web-opening and $I_{5}$ is the total number of web-opening of the Angelina" steel beam. The building elements are selected from among the ready-made profile lists defined in the specification such as wide-headed I-profiles on the market. The aim is to minimize the weight of the building. If weight of the sinusoidal web-expanded steel beam is expressed as $W_{S S I B}$, the objective function will be like Equation 11.

Objective function:min: $W_{S S I B}=\rho_{S} x A_{S S I B} x L_{S S I B}-\rho_{S}\left(4 x\left(\int_{0}^{x} y x d x\right) x t_{w} x N_{\text {hole }}\right)$ (11)

In here, $\rho_{s}$ is density of steel is used I-sections, $A_{S S I B}$ is the cross-section area of the beam, $L_{S S I B}$ is span length, $y$ is curve of sinusoidal function and $N_{\text {hole }}$ is the total number of sinusoidal opening in the beam. The functional expression of the sinusoidal curve will be formed in the beam is as follows.

$$
y=\left(0,5 x \frac{a}{2}\right) x \sin \left[\pi\left(\frac{x}{b}+\frac{3}{2}\right)\right]+\frac{a}{4}
$$

In the optimal design of sinusoidal web-expanded steel beams, geometric constraints, which must provide some geometric and behavioral constraints, are shown in the following equations. The geometric constrainsrs are expressed below in terms of height values of web-opening $(a)$, the horizontal length of each sinusoidal curve $(b)$, the length of the flat portion of the opening $(e)$, the initial heigh of the beam $\left(H_{\text {first }}\right)$, and the final heigth of the beam $\left(H_{\text {end }}\right)$ at the end of the cutting and welding process.

$$
\begin{gathered}
1,4 H_{\text {first }}-H_{\text {end }} \leq 0(13) \\
H_{\text {end }}-1,7 H_{\text {first }} \leq 0(14) \\
3 a-(2 b+e) \leq 0(15) \\
(2 b+e)-5 a \leq 0(16)
\end{gathered}
$$

\subsection{Behaviour Constrains of Web-expanded Beams}

As a result of the experimental works carried out under vertical loads for web-expanded beams; different modes of collapse have been observed in the beam by depending on the geometry of the beam opening, the slenderness of beam, the loading type and the conditions of the lateral supports. Some behavior must be taken into account in order to avoid imperfections that may occur under load combinations of beams.

\subsubsection{Seconder (Vierendeel) Bending Capacity:}

In these beams, the elasticity capacity of the lower and upper parts under bending condition must be verified. When the beam is subjected to shear, the T-sections at the top and bottom of the beam opening must carry the primary and secondary moments as well as the applied shear (Equation 17-19). The primary moment is the classical bending moment on the beam section. Transferring the shear forces along each opening as shown in detail in Figure 2 causes a 
secondary bending moment (vierendeel moment).

$$
\begin{aligned}
& \frac{P_{0}}{D_{w}}+\frac{M}{M=} \leq 1.0 \\
& P_{0}=T \cos \theta-\frac{V}{2} \sin \theta(18) \\
& M=T\left(x_{S 0}-x_{0}\right)+\frac{V}{2}\left(\frac{H_{S}}{2}-x_{S 0}\right)
\end{aligned}
$$

\subsubsection{Shear Capacity:}

Three shear forces control are taken in design of web-expanded beams. The first of these is the shear force in the supports. Constrain in $20^{\text {th }}$ inequality provides that the value of the shear force $\left(V_{\max s u p}\right)$ on the support does not exceed the maximum shear force capacity of the beam section $\left(P_{v}\right)$.

$V_{\max s u p}-P_{v} \leq 0(20)$

$P_{v}=0.6 x p_{y} x(0.9 x$ Area of web of the beam in supports) (21)

In addition to the first verification, the vertical shear force control (Equation 22) is performed. The sum of the shear forces of the lower and upper T-sections which have been formed due to the beam opening gives the total shear capacity of the beam. The shear force in the vertical direction on the beam due to the applied load combination $V_{0 \max }$ should not exceed value of $P_{v y}$.

$V_{0 \text { max }}-P_{v y} \leq 0$ (22)

$P_{v}=0.6 x p_{y} x(0.9 x$ Area of the lower and upper T - sections $)$

Finally, the lateral shear force control is performed (Equation 24). Lateral shear force is occurred on the web of beam due to the change of the axial forces on the upper part of the beam (Figure 4). Lateral force in the web region of the beam $\left(V_{H \text { max }}\right)$ must be less than the value of the lateral shear force $\left(P_{v h}\right)$.

$$
\begin{aligned}
& V_{H \text { max }}-P_{v h} \leq 0 \text { (24) } \\
& P_{v h}=0.6 x p_{y} x(0.9 x \text { Minimum area of web) (25) } \\
& V_{i+1}=V_{i}(26) \\
& M_{i}=T_{i}\left(H_{S}-2 x_{0}\right)(27) \\
& V_{h}=T_{i+1}-T_{i}=V_{i+1} \frac{S}{H-9 v_{n}} \text { (28) }
\end{aligned}
$$

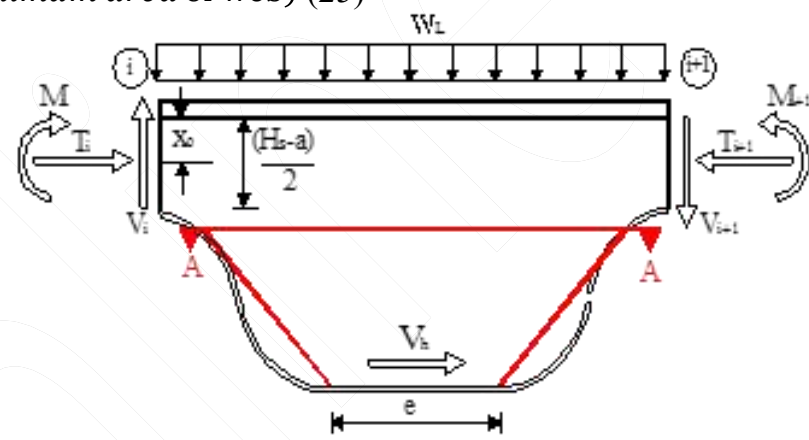

Figure 4. Lateral shear in the upper web of the beam

\subsubsection{Rupture in the welding zone:}

In the case of short welding lenght on web-expanded beams under load in order to reduce the secondary moment to be generated in T-sections of beam or in case of thin welding thickness, rupture may occur in connection area of welding. The formulation of the minimum " $a$ " value, which represents the thickness of the double-sided weld made in these, is shown in Equation 29. In this expression, the lateral shear force in the welding regions $\left(V_{h}\right)$, length of welding $(w)$, constant coefficient $\left(\gamma_{w}\right)$ are represented. The values $f_{u}$ and $\beta_{w}$ are determined according to the steel material properties.

$$
a \geq \frac{V_{h} x \beta_{w} x \sqrt{3}}{w f_{u} \gamma_{w}}
$$




\subsubsection{Web-Buckling}

As shown in Figure 4, the maximum moment at intercection $\left(M_{\max }\right)$ and resultant value $\left(\sigma_{w}\right)$ should not exceed the maximum permissible moment $\left(M_{w \max }\right)$ and $\left(\sigma_{w-\text { allow }}\right)$ values (Equation 30$)$.

$M_{A-A \max }-M_{w \max } \leq 0(30)$

\section{Design Sample}

It is assumed that the steel beam which is demonstrated in Figure $\mathbf{5}$ is decided to be a web-expanded beam in the form of a sinusoidal curve. In addition to its own weight, the beam is subjected to a four-point bending. Permissible total displacement for beam under live loads is limited to $17 \mathrm{~mm}$. Modulus of elasticity is $205 \mathrm{kN} / \mathrm{mm}^{2}$ and design stress of Angelina" steel beam (St-37) is $27.5 \mathrm{kN} / \mathrm{mm}^{2}$.

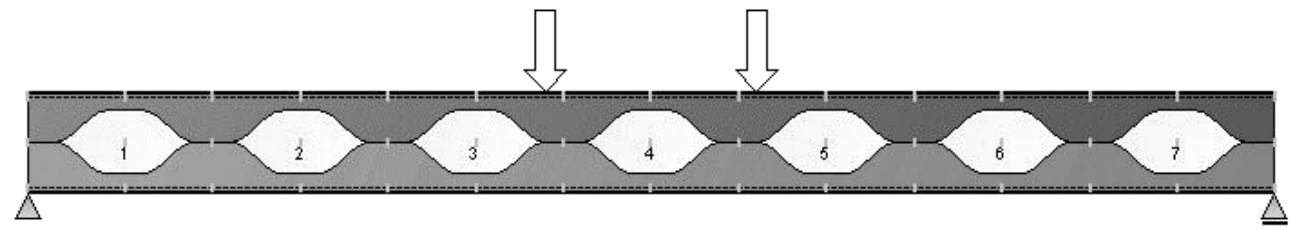

Figure 5. Angelina" steel beam

In the optimum design problem, the sequence number of the hot rolled I-section, height of web-opening, horizontal length of sinusoidal curve, and distance between centers of opening, length of linear sections and total number of openings in beam are taken as design variables. For this purpose, a design pool is prepared consisting of standard I-section beam profiles ranging from NPI-100 to NPI-750, web opening heights ranging from $70 \mathrm{~mm}$ to $600 \mathrm{~mm}$ and total number of openins in the ranging from between 2 to 40. The design constraints include displacement constraints, flexural capacity of beam, shear capacity, flexural and buckling capacity of beam, vierendeel bending capacity of the upper and lower parts of the web-expanded beam and local buckling that may occur at the upper flange of the Angelina steel beam.

Different parameter of Harmony Search (HS) and Particle Swarm (PS) method have been tested for optimum results in Angelina ${ }^{\mathrm{TM}}$ beam design. The harmoni memory matrix () and the number of particles () are considered for both optimization methods as equal and 10. and ,which are the other parameters of the HS method, are taken as 0.8 and 0.35 , respectively. Among the design parameters of the PS method, and were chosen as 1, as 2 . The first matrixes are found by using these coefficients. The optimum design results of the web-expanded beam with sinusoidal opening using HS and PS method are given in Table 1. In both stochastic search methods, the HS algorithm finds, as shown in Figure 6, the IPE-SB300 beam with a weight of $225.1 \mathrm{~kg}$ after 10000 iterations using, and parameters as $30,0.80$ and 0.35 respectively for this beam. So, HS method is considered due to its weigher design.

\begin{tabular}{|l|l|l|l|l|l|l|}
\hline $\begin{array}{l}\text { Optimum Search } \\
\text { Method }\end{array}$ & $\begin{array}{l}\text { Optimum } \\
\text { Section } \\
\text { Design (UB) }\end{array}$ & $\begin{array}{l}\text { Distance betwee } \\
\mathbf{n} \text { openings } \\
(\mathbf{m m})\end{array}$ & $\begin{array}{l}\text { Height of } \\
\text { opening } \\
(\mathbf{m m})\end{array}$ & $\begin{array}{l}\text { Horizantal } \\
\text { distance of } \\
\text { sinusoidal } \\
\text { curve }\end{array}$ & $\begin{array}{l}\text { Total number } \\
\text { of opening }\end{array}$ & $\begin{array}{l}\text { Minimum } \\
\text { Weight (kg) }\end{array}$ \\
\hline $\begin{array}{l}\text { HS } \\
\text { Algorithm }\end{array}$ & NPI-A_300 & 730.3 & 268 & 215.2 & 7 & 225.1 \\
\hline $\begin{array}{l}\text { PS } \\
\text { Algorithm }\end{array}$ & NPI-A_300 & 737.9 & 259 & 211.6 & 7 & 226.3 \\
\hline
\end{tabular}

Table 1. Comparison of results for optimum designed Angelina" beam 

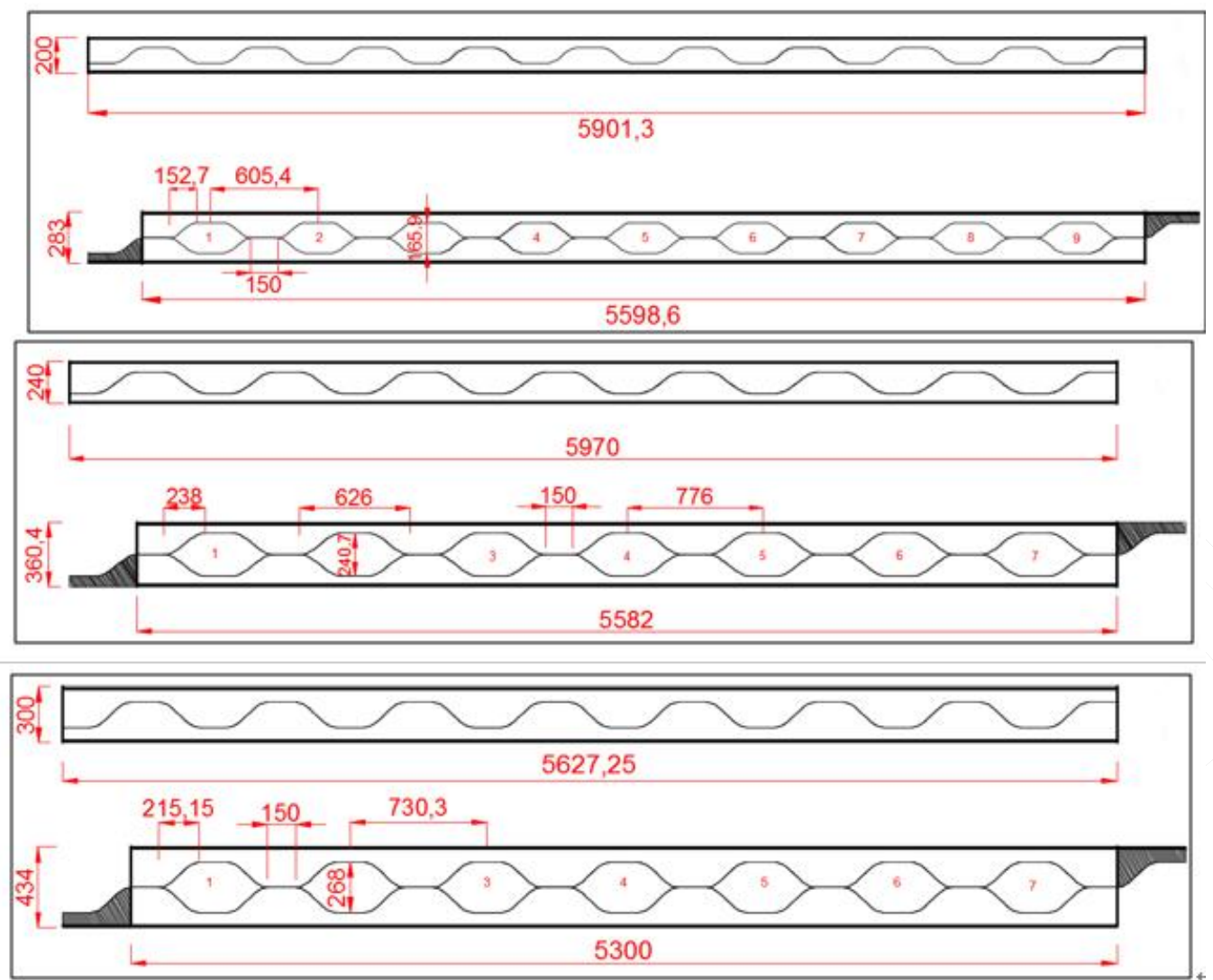

Figure 6. Appearance of NPI_A_200, NPI_A_240 and NPI_A_300 Angelina" beams after cutting and post-welding

\subsection{Experimental studies of Angelina ${ }^{\mathrm{TM}}$ steel beam}

\subsubsection{Fabrication of Angelina ${ }^{\mathrm{TM}}$ steel beam in the labrotory}

The I-section profile of the steel is formed by cutting in sinusoidal forms along the web of the profiles and the lower and upper parts are shifted and re-joined by welding (Figure 7). Cutting process of the fabrication of web-expanded steel beams is performed by computer-based numerical control (CNC) method in order to obtain opening in the web of the I-section beam.

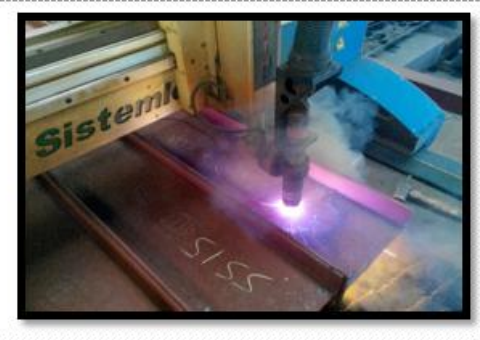

(a)

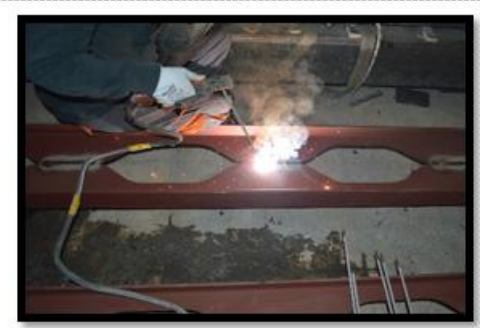

(c)

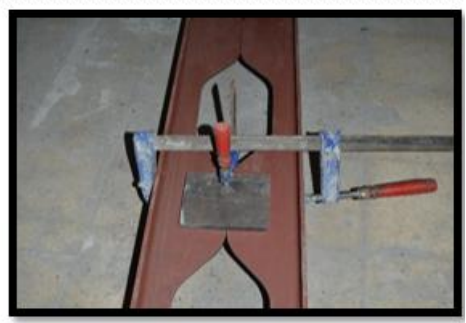

(b)

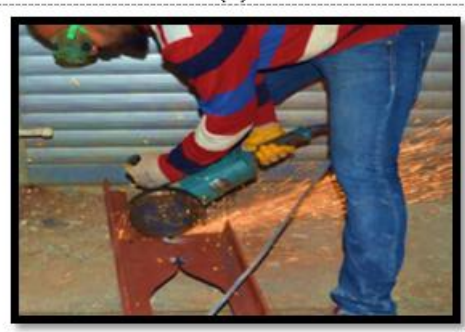

(d)

Figure 7. a) Cuttint process by $\mathrm{CNC}$, b) Shifting and joining of the lower and upper parts, c) Welding process, d) Cutting of waste parts of Angelina" steel beams 


\subsubsection{Tests of Angelina ${ }^{\mathrm{TM}}$ Steel Beams}

In the experimental part of research, the ultimate load carrying capacities of steel Angelina ${ }^{\mathrm{TM}}$ beams are tested in a self reacting frame. The tested Angelina ${ }^{\mathrm{TM}}$ beam specimens are designed by using HS optimization method as explained in the previous section. The beam spans are chosen to be 5 meters because of the fact that the Angelina ${ }^{\mathrm{TM}}$ steel beams are used to pass large spans which generally do not require column supports. Two repetitions were applied for each beam type. For this purpose, six in total web-expanded steel beam, NPI_A_200, NPI_A_240, and NPI_A_300 which have opeining in sinusoidal form, are optimally designed by using stochastic search methods (Table 3). The loading frame which are carried the tests out allows to perform bending tests has $1000 \mathrm{kN}$ loading capacity. In this system, the load capacities and behaviors of the Angelina ${ }^{\mathrm{TM}}$ beams which are produced from web-expanding NPI 200, NPI 240 and NPI 300 profiles were investigated under three-points, four-points and distributed loads respectively.

\begin{tabular}{|l|l|l|}
\hline \hline Test & Loading Type & Number of Test \\
\hline \hline NPI_A_200 & Three-point loading & 2 \\
\hline NPI_A_240 & Distributed loading & 2 \\
\hline NPI_A_300 & Four-point loading & 2 \\
\hline
\end{tabular}

Table 2. Naming of the beams and loading types wich will be apply

A load cell which have $1000 \mathrm{kN}$ measurement capacity is installed to hydraulic piston. And, it is calibrated in order to read the load which is occurred during test with more sensitive values (Figure 8a). The beam is placed on one of the endpoints as constant and the other one as unconstant platforms by taking care that it is not occurred an eccentric loading (Figure 8b-c).

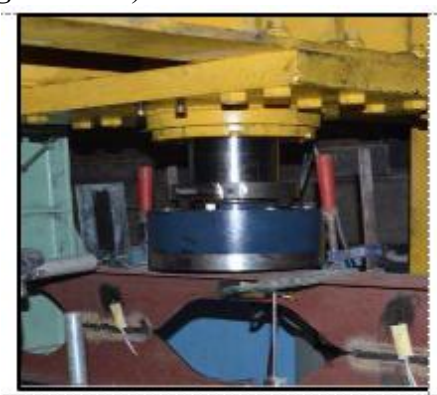

(a)

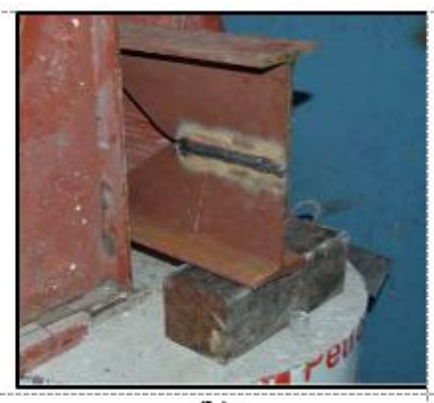

(b)

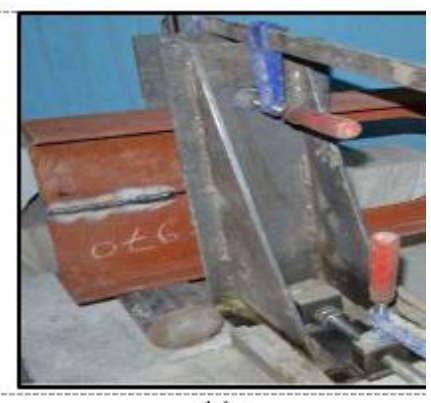

(c)

Figure 8. (a) Load cell, (b) Constant support system, (c) Unconstant support system

Displacement gauges (linear variable differential transformers-LVDT) are placed horizontally in the middle of the upper flansh of the beam to read lateral displacement and they are placed vertically to the middle point of the lower and upper flansh of the beam to mesure vertical displacement which is occurred due to the result of the loading in the beams. In addition, strain gauges are placed on both sides of the web to determine strain changes in the Angelina ${ }^{\text {" }}$ beam. The positions of the displacement gauges and strain gauges on the beam are also shown in Figure 9.

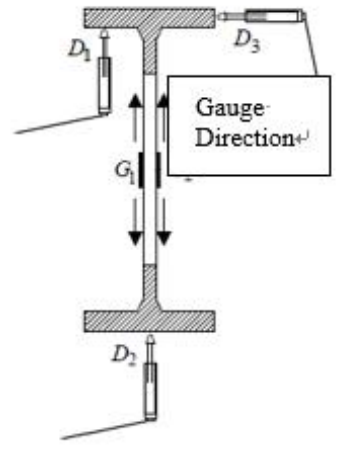

Figure 9. Positions of the LVDT and strain gauges 


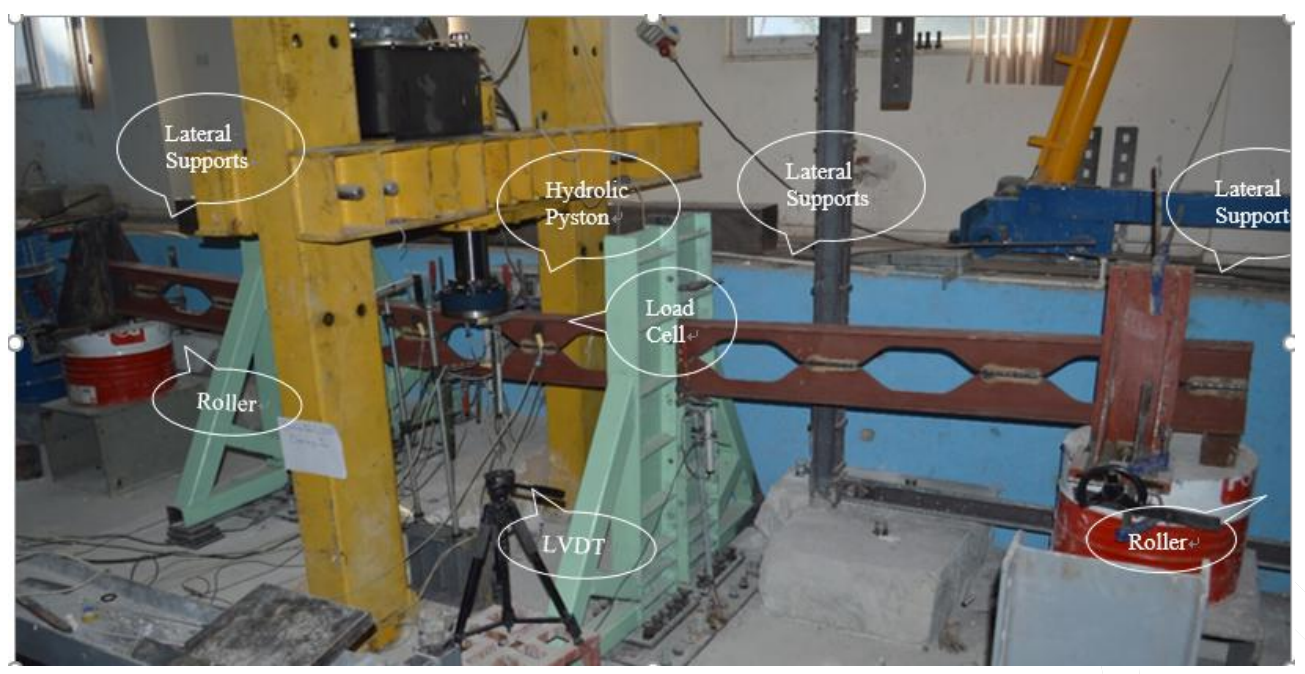

Figure 10. Test Setups of Lateral Supported Angelina" Steel Beam

The web-expanded steel beam is cut along the web of the I-section beams and the resultant lower and upper parts are shifted and re-welded each other. As a result of their re-assembly, their section coefficients and their moment of inertia increase according to heights increases. Thus, it is possible to increase the load carrying capacities under the vertical load, which is the basic characteristic of these beams. On the other hand, that the bending stiffness, warping and torsional stiffness of the deep and slender web of these beams remain constant increase the risk of lateral buckling compared to the initial conditions of these beams. In the tests, lateral supports were placed at regular intervals to prevent lateral buckling. The experimental setup in the loading frame under vertical loading of the Angelina" beams is shown in Figure 10.

\subsection{Tests of NPI 200}

Spans of all the test samples have been taken as 5 meters considering the passing potentials of the wide spans which do not have the middle column supports. In addition, tests were carried out on the beams in such a way that two tests for each design were carried out for the experimental purposes and the load carrying capacities were determined by averaging result of these two tests. In this context, 6 ( $\mathrm{six}$ ) different bending tests of Angelina ${ }^{\mathrm{TM}}$ beams are produced from web-expanding NPI 200, NPI 240 and NPI 300 profiles are tested. under three-points, four-points and distributed loads respectively.

\subsubsection{Three-point loading condition of Angelina ${ }^{\mathrm{TM}}$ beams}

The experimental setup in the loading frame with Angelina " ${ }^{\text {" }}$ steel beams under three-point loading is shown in Figure 11. The hydraulic piston with $1000 \mathrm{kN}$ capacity integrated in the loading frame acts from the exact center of the 5 meters clear span of the beam.
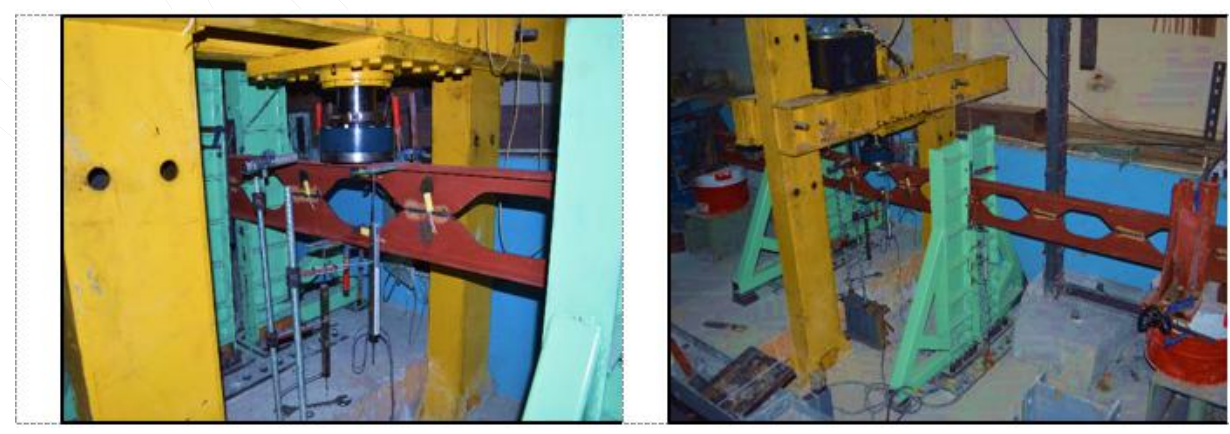

Figure 11. NPI_A_200 beam under three-point loading condition

\subsubsection{NPI_A_200_TEST_1}

The first sinusoidal beam which is detailed geometric and material properties in Figure 6 is tested under singular 
loads. As a result of the test, the load carrying capacity of the beam is measured as $73.58 \mathrm{kN}$. In this test, it is observed that the beam does not undergo any lateral displacement up to $70 \mathrm{kN}$ but lateral displacement from the top of the beam is seen after this value (Figure 12).

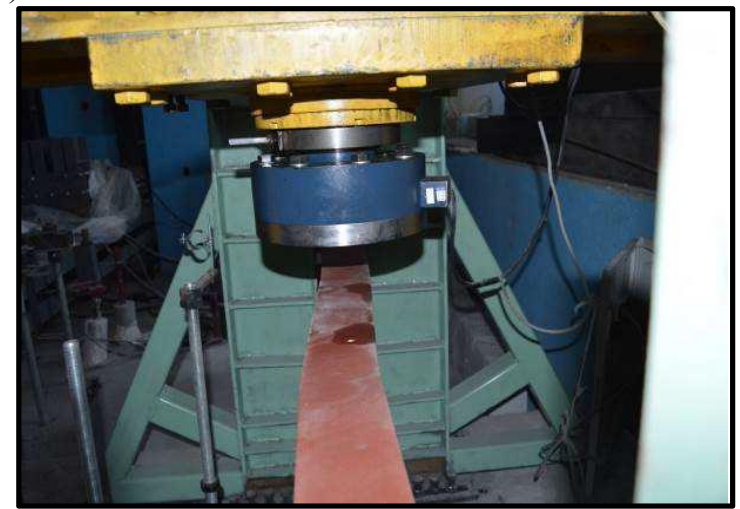

Figure 12. NPI_A_200_Test_1; Lateral displacement condition under three-point loading

Relation between the maximum lateral displacement of the beam and the load carrying capacity of the test result is given in Figure 13. As is seen, a significant lateral displacement is measured in the middle of the beam after the loading exceed to $70 \mathrm{kN}$.

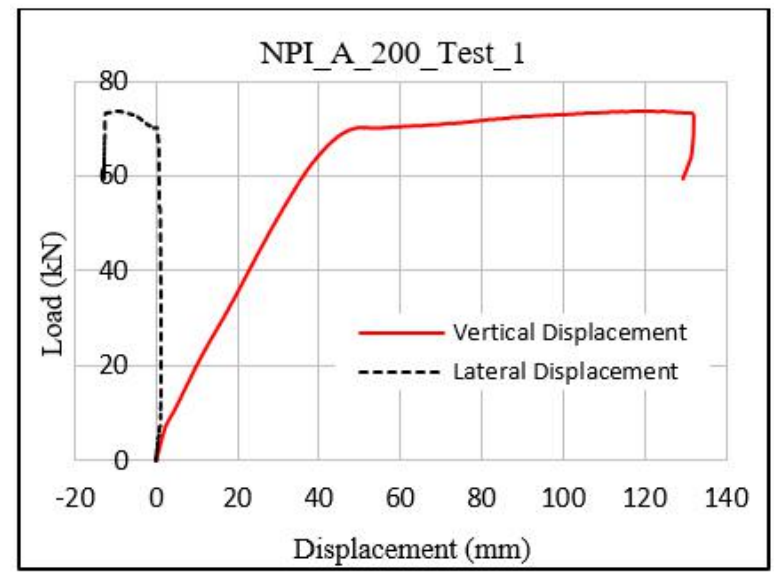

Figure 13. NPI_A_200_Test_1; Force-displacement chart of three-point loading

\subsubsection{NPI_SB_200_TEST_2}

The second Angelina " beam which is detailed geometric and material properties in Fig. 6 is tested under three-point loading. As a result of the test, the load carrying capacity of the beam is measured as $75.05 \mathrm{kN}$. In this test, it is observed that the beam does not undergo any lateral displacement up to $71.6 \mathrm{kN}$ but lateral displacement from the top of the beam is seen after this value (Fig. 14).

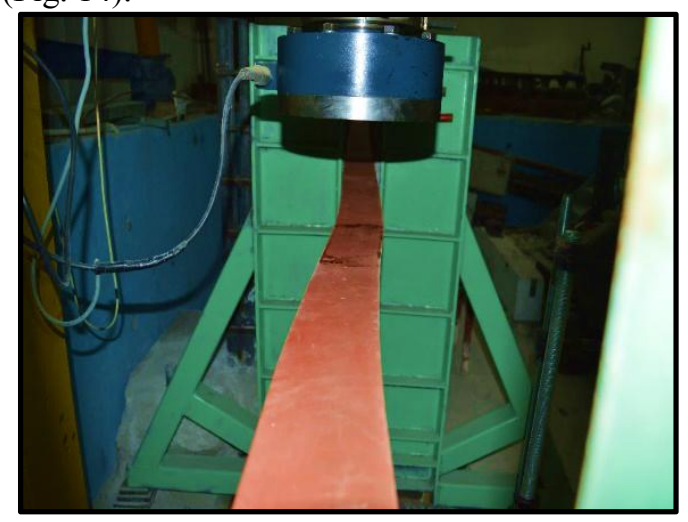

Figure 14. NPI_A_200_Test_2; Lateral displacement condition under three-point loading 
Relation between the maximum lateral displacement of the beam and the load carrying capacity of the test result is given in Figure 15. As is seen, a significant lateral displacement is measured in the middle of the beam after the loading exceed to $71.6 \mathrm{kN}$.

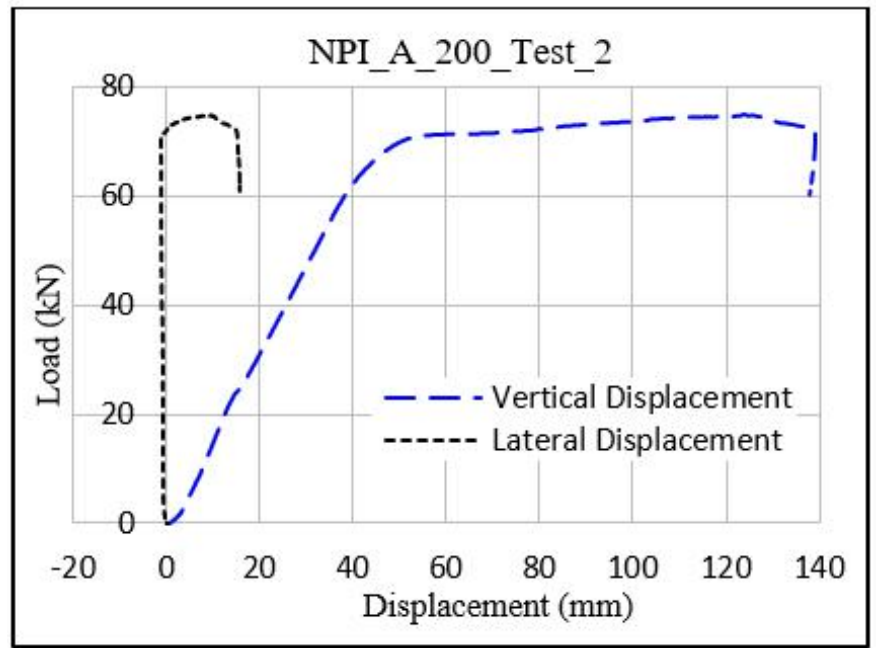

Figure 15. NPI_A_200_Test_2; Force-displacement chart of three-point loading

The maximum vertical displacement for the load carrying capacities $(73.58 \mathrm{kN}$ and $75.05 \mathrm{kN}$, respectively) obtained from the three-point loading tests for NPI_A_200 Angelina" steel beams are given in Figure 16.

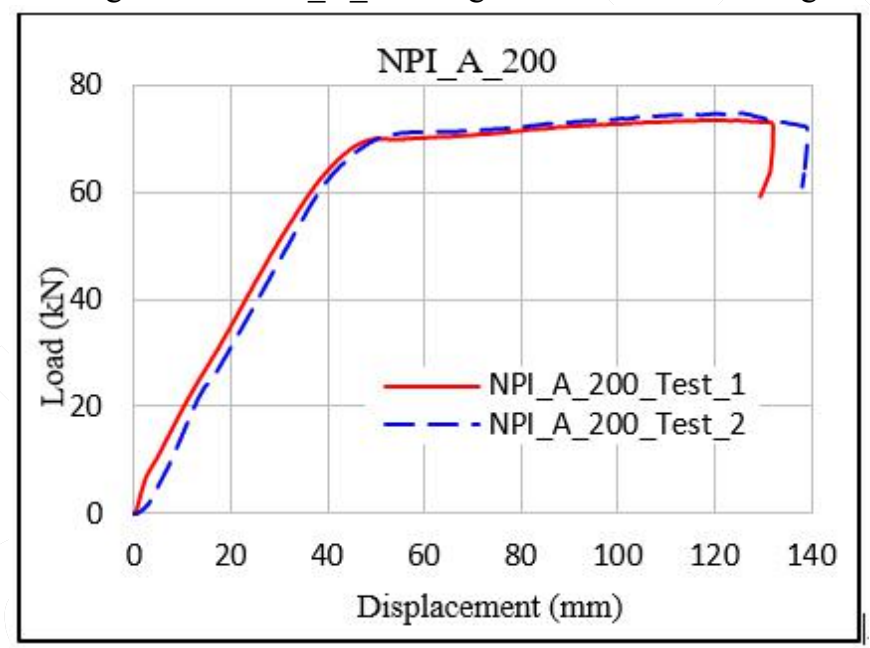

Figure 16. NPI_A_200 Force-displacement chart of three-point loading

\subsubsection{Distributed loading condition of Angelina ${ }^{\mathrm{TM}}$ beams}

The experimental setup in the loading frame with Angelina ${ }^{\mathrm{TM}}$ steel beams under three-point loading is shown in Figure 17. The hydraulic piston which have $1000 \mathrm{kN}$ capacity and is integrated in the loading frame effect via the stiffened beam along the $153 \mathrm{~cm}$ to exact center of the $5 \mathrm{~m}$ clear span. And, there is $173.5 \mathrm{~cm}$ from both supports to stiffened beam. Displacement gauges (linear variable differential transformers-LVDT) are placed horizontally in the middle of the upper flansh of the beam to read lateral displacement under the distributed loding and they are placed vertically to the middle point of the lower and upper flansh of the beam to mesure vertical displacement which is occurred due to the result of the loading in the beams. In addition, strain gauges are placed on both sides of the web to determine strain changes in the Angelina" beam. 


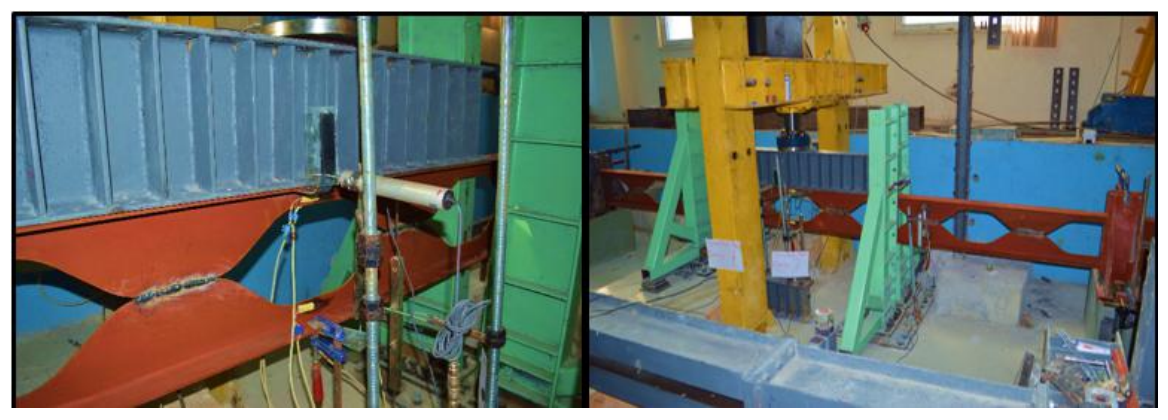

Figure 17. NPI_A_240 Test setup

\subsubsection{NPI_A_240_TEST_1}

The first sinusoidal beam which is detailed geometric and material properties in Table 2 is tested under distributed loading. As a result of the test, the load carrying capacity of the beam is measured as $135.25 \mathrm{kN}$. In this test, web buckling and vierendial bending that occurs under the shear force around the web-opening at the top of the beam is observed after this value (Figure 18).
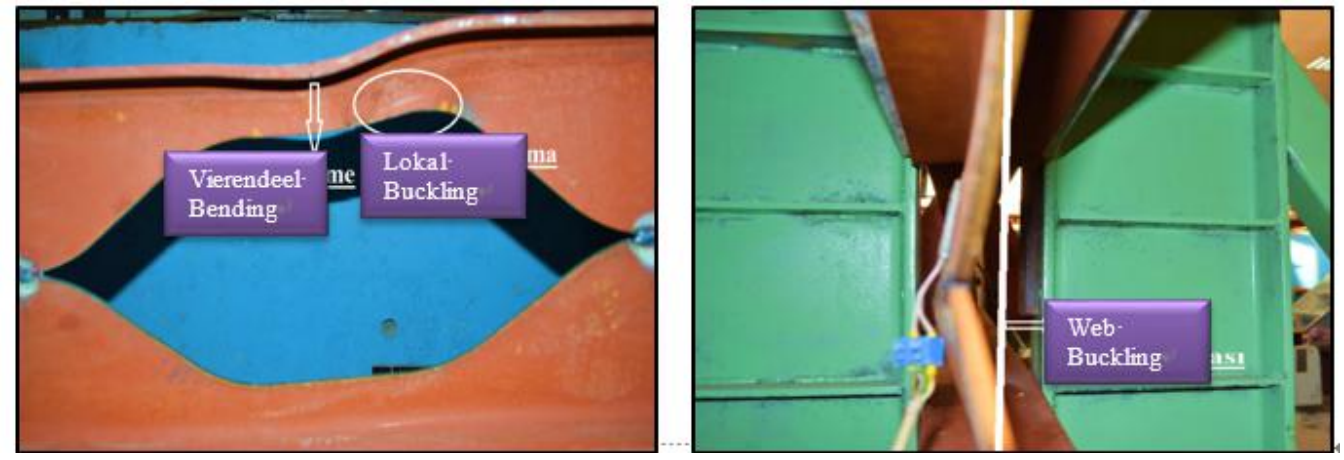

Figure 18. NPI_A_240_TEST_1; Colapse status under distributed load

Relation between the maximum lateral displacement of the NPI_SB_240 beam and the load carrying capacity which is obtained from test result is given in Figure 19. As shown in this figure, a significant lateral displacement is measured as little as to be ignored in the middle of the beam.

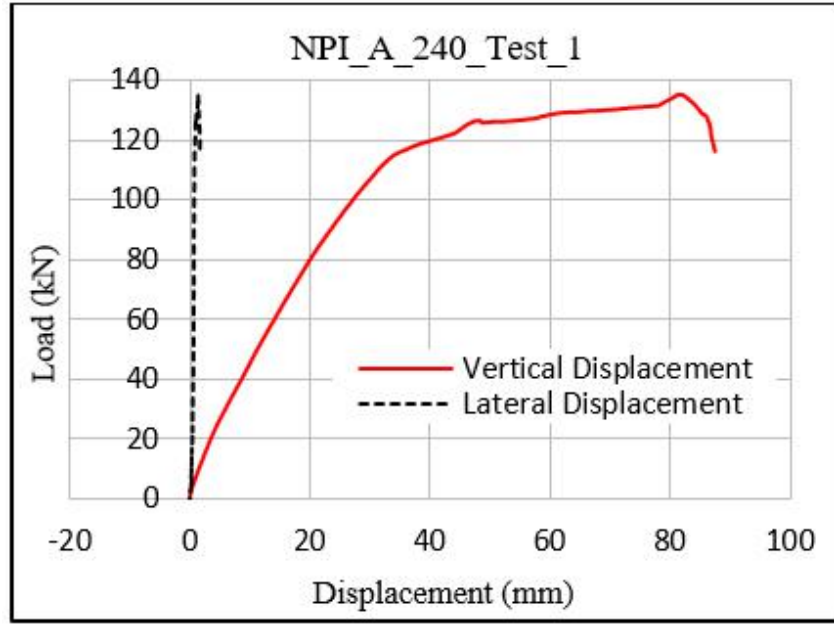

Figure 19. NPI_A_240_TEST_1; Force-displacement chart of Angelina"' steel beam

\subsubsection{NPI_A_240_TEST_2}

The second sinusoidal beam which have same geometric and material properties with first one is tested under distributed loading. As a result of the test, the load carrying capacity of the beam is measured as $130.34 \mathrm{kN}$. During the test, web buckling, vierendial bending that occurs under the shear force and local buckling around the web-opening is observed after this value (Figure 20). 

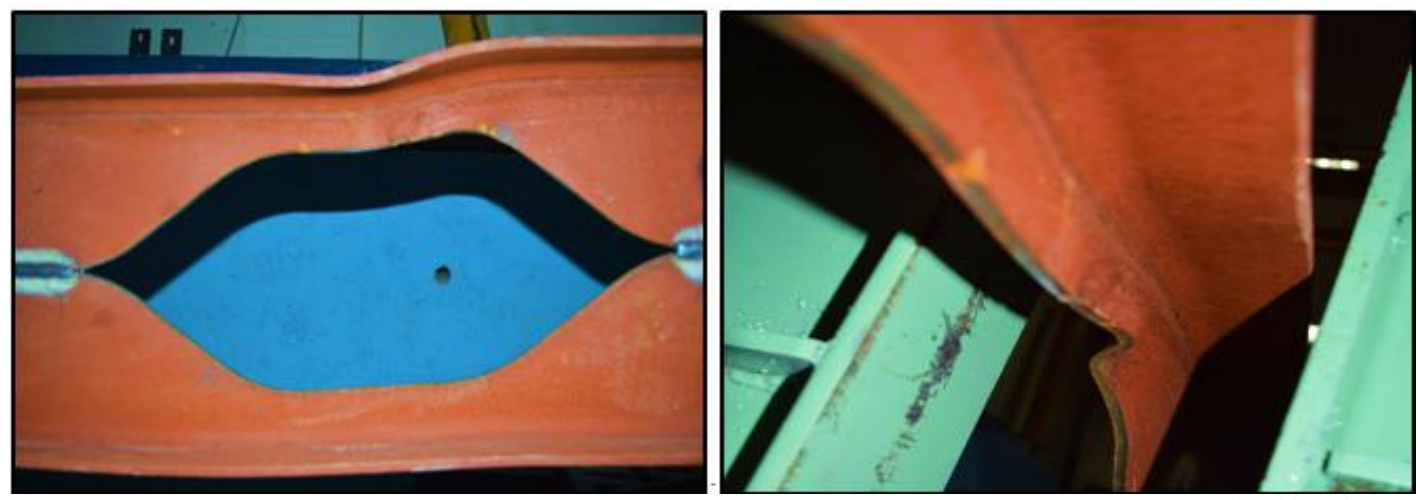

Figure 20. NPI_A_240_TEST_2; Colapse status under distributed load

Relation between the maximum lateral displacement of the second NPI_SB_240 beam and the load carrying capacity which is obtained from test result is given in Figure 21. As shown in this figure, a significant lateral displacement is measured as little as to be ignored in the middle of the beam.

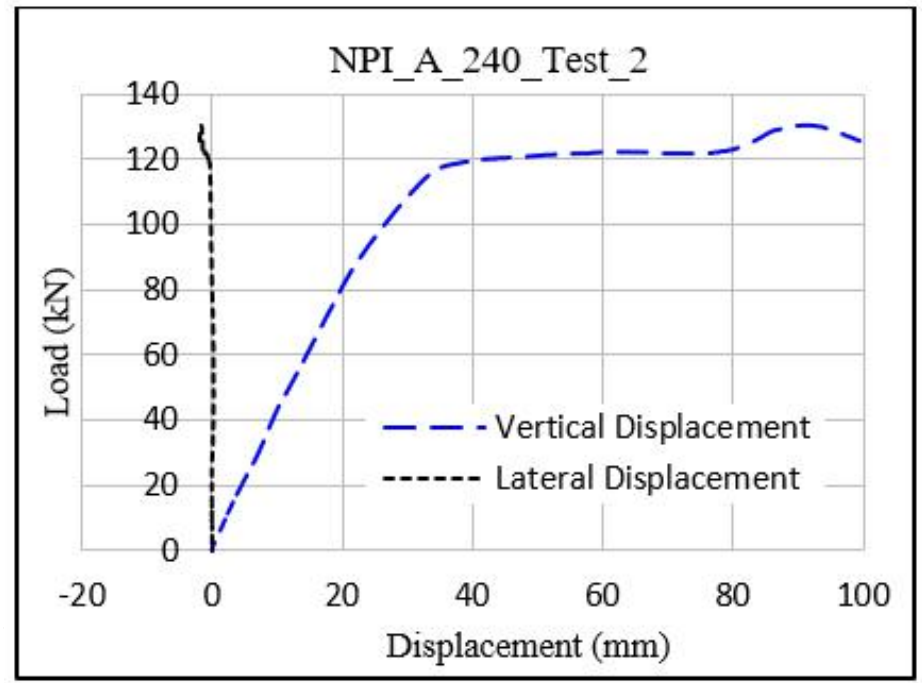

Figure 21. NPI_A_240_TEST_2; Force-displacement chart of Angelin" steel beam

The maximum vertical displacement for the load carrying capacities (135.25 $\mathrm{kN}$ and $130.34 \mathrm{kN}$, respectively) obtained from the distributed loading tests for NPI_A_240 Angelina" ${ }^{\text {tI }}$ steel beams are given in Figure 22.

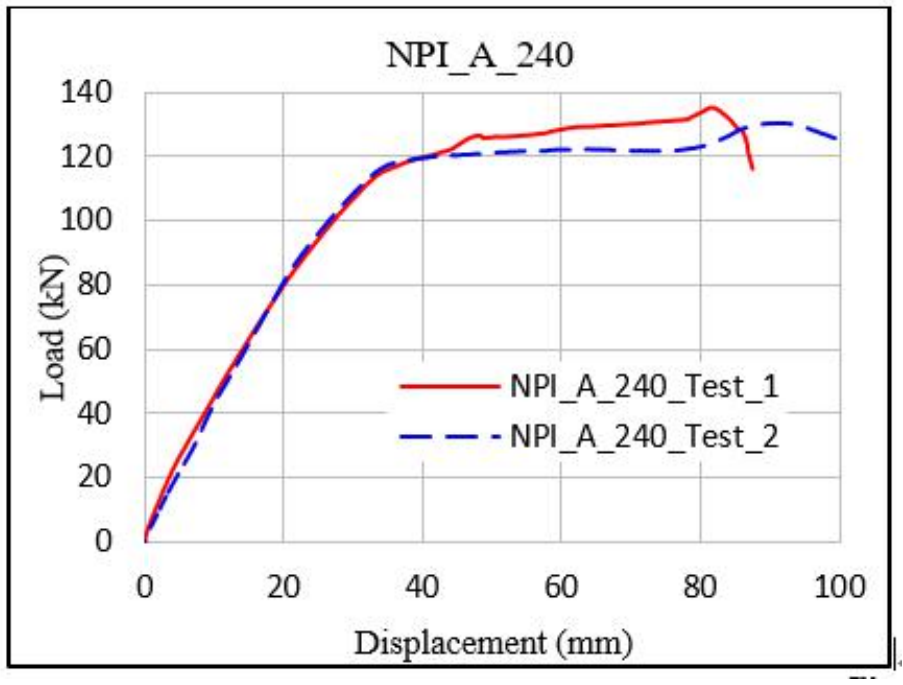

Figure 22. NPI_A_240 Force-displacement chart of Angelina" steel beam 


\subsubsection{Four-point loading condition of Angelina ${ }^{\mathrm{TM}}$ beams}

The experimental setup in the loading frame with Angelina ${ }^{\text {II }}$ steel beams under four-point loading is shown in Figure 23. The hydraulic piston which have $1000 \mathrm{kN}$ capacity is integrated to the loading frame which effect via the stiffened beam and 2 aparatus at the two point which have $73 \mathrm{~cm}$ interval. And, there is $213.5 \mathrm{~cm}$ distance from both supports to loading points. Displacement gauges (linear variable differential transformers-LVDT) are placed horizontally in the middle of the upper flansh of the beam to read lateral displacement under the four-point loding and they are placed vertically to the middle point of the lower and upper flansh of the beam to mesure vertical displacement which is occurred due to the result of the loading in the beams. In addition, strain gauges are placed on both sides of the web to determine strain changes in the Angelina " beam.

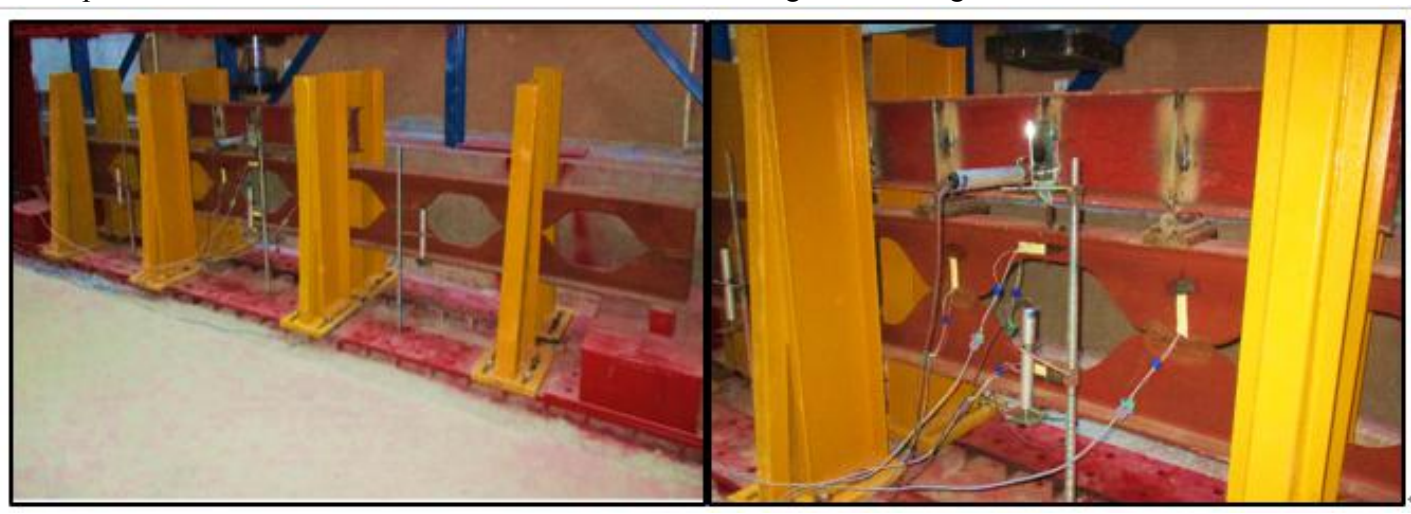

Figure 23. NPI_A_300; Four-point bending conditions

\subsubsection{NPI_A_300_TEST_1}

The first sinusoidal beam which is detailed geometric and material properties in Figure 6 is tested under four-point loading. As a result of the test, the load carrying capacity of the beam is measured as $135.25 \mathrm{kN}$. In this test, web buckling and vierendial bending that occurs under the shear force around the web-opening at the top of the beam is observed after this value (Figure 24).

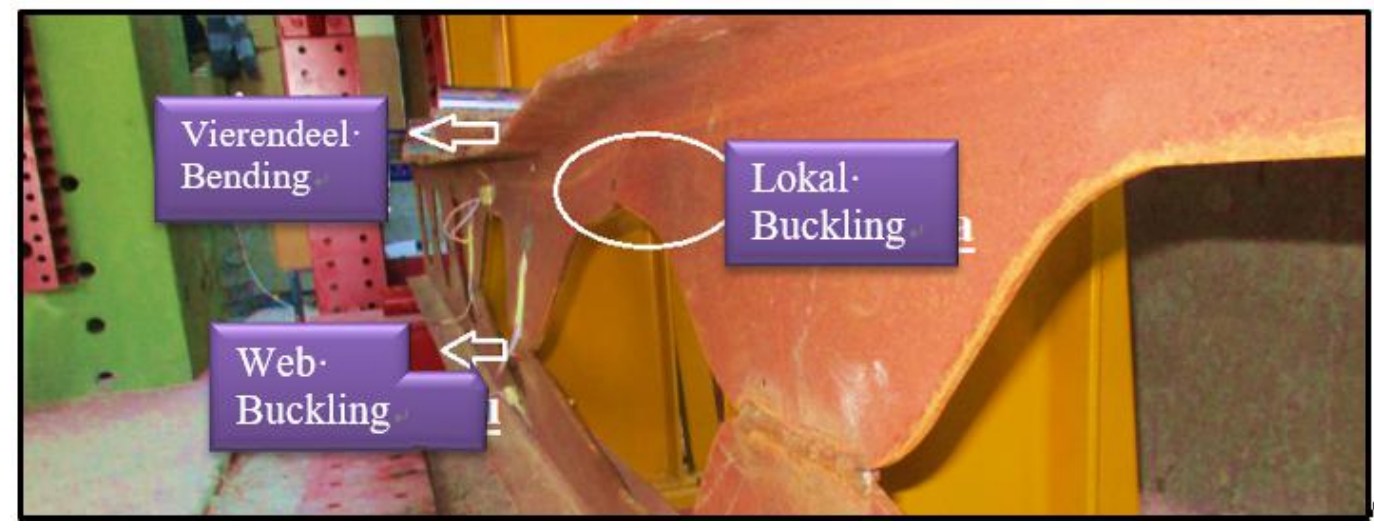

Figure 24. NPI_A_300_TEST_1; Collapse under four-point loading

Relation between the maximum lateral displacement of the NPI_A_240 beam and the load carrying capacity which is obtained from test result is given in Figure 25. As shown in this figure, a significant lateral displacement is measured as little as can be ignored in the middle of the beam. 


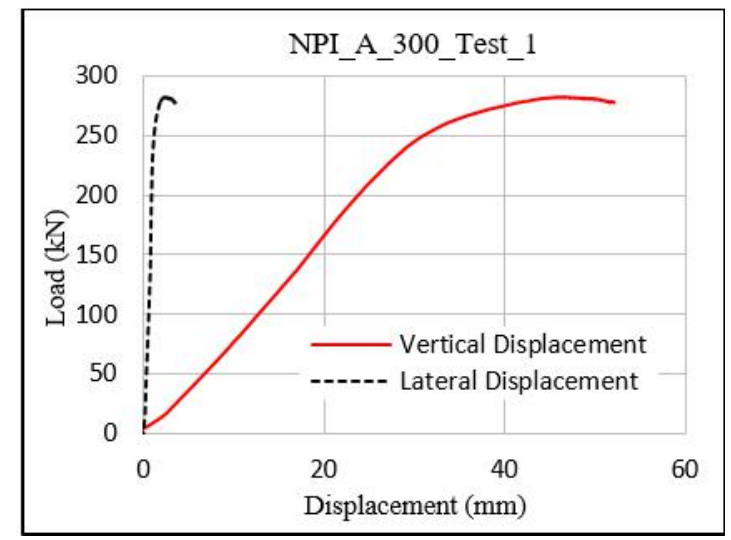

Figure 25. NPI_A_300_Test_1; Force-displacement chart of Angelina" steel beam

\subsubsection{NPI_A_300_TEST_2}

The second sinusoidal beam which have same geometric and material properties with first one is tested under four-point loading. As a result of the test, the load carrying capacity of the beam is measured as $270.46 \mathrm{kN}$. During the test, web buckling, vierendial bending and local buckling around the web-opening is observed after this value (Figure 26).

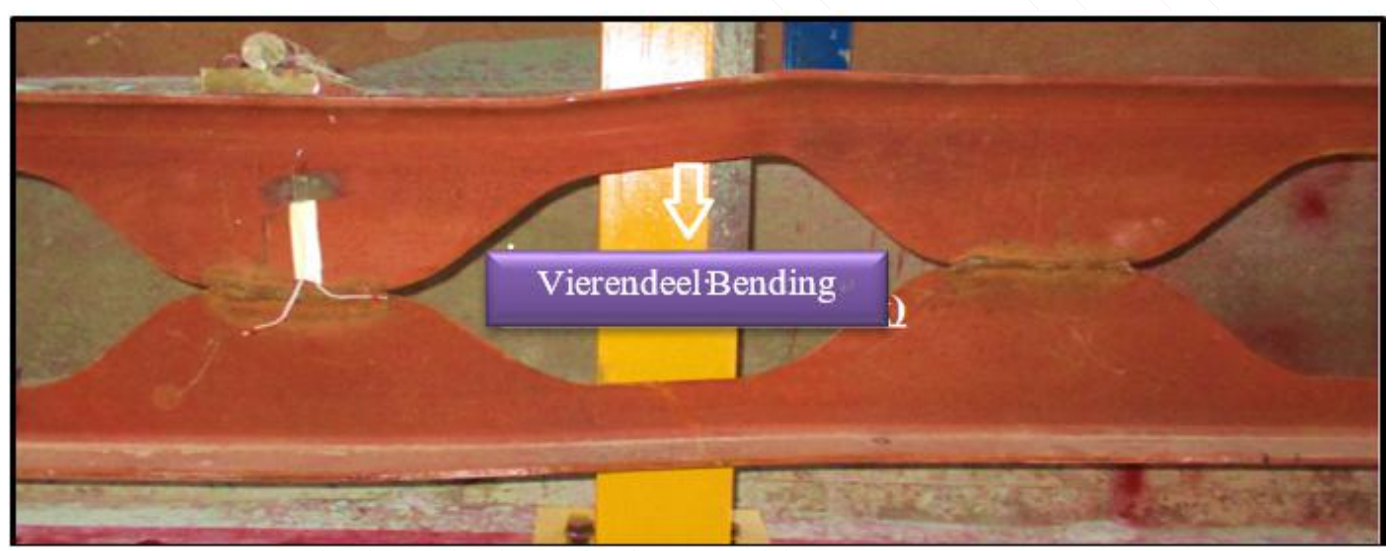

Figure 26. NPI_A_300_TEST_2; Collapse under three-point bending

Relation between the maximum lateral displacement of the NPI_SB_240 beam and the load carrying capacity which is obtained from test result is given in Figure 27. As shown in this figure, a significant lateral displacement is not measured in the middle of the beam.

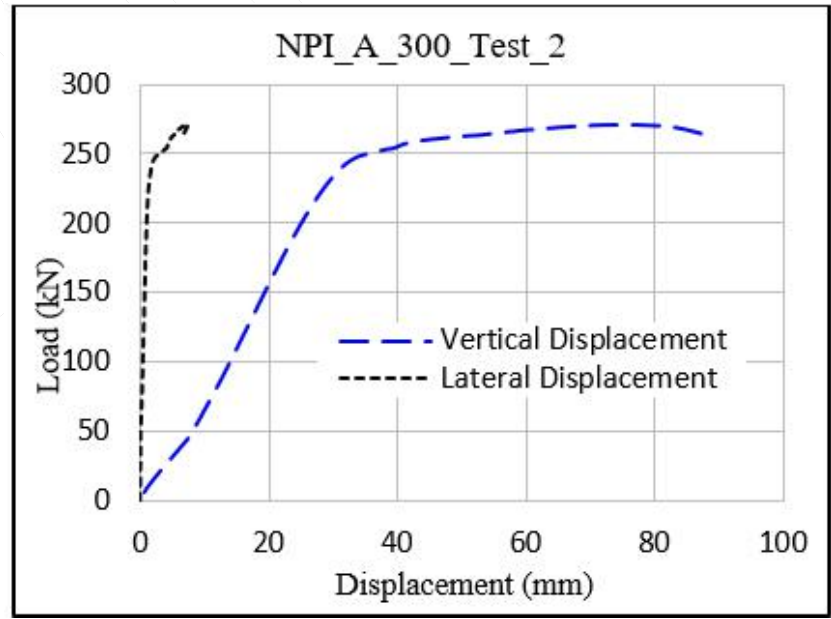

Figure 27. NPI_A_300_Test_2; Force-displacement chart of Angelina" steel beam

The maximum vertical displacement for the load carrying capacities $(282,48 \mathrm{kN}$ and $270.46 \mathrm{kN}$, respectively) 
obtained from the three-point loading tests for NPI_SB_300 Angelina ${ }^{\text {"t }}$ steel beams are given in Figure 28.

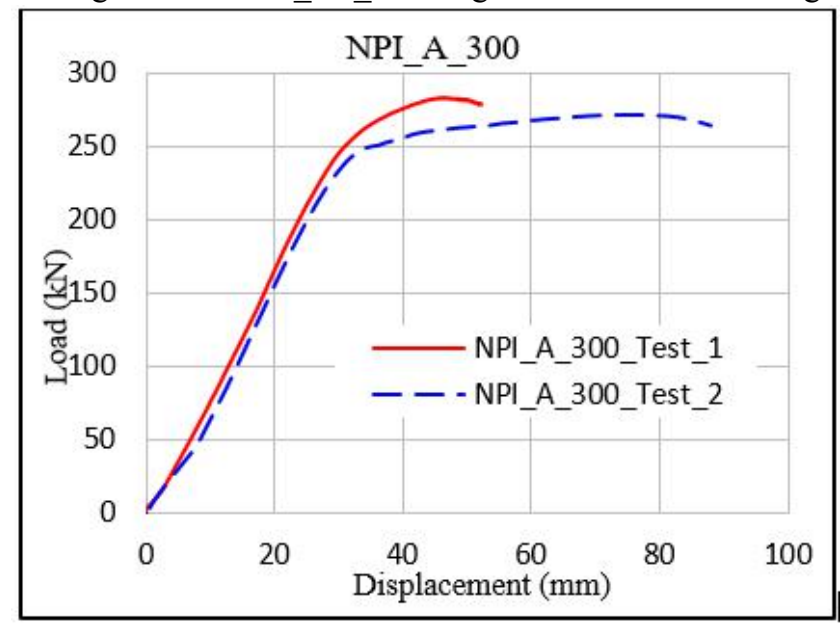

Figure 28. NPI_A_300; Force-displacement chart of Angelina ${ }^{\text {w }}$ steel beam

\section{Results}

In this study, optimum design problem of sinusoidal web-opening steel beams; profile section is solved under geometric and behavioral constraints using design variables such as the height of the web-opening which is formed in the beam, the horizontal length of each sinusoidal curve, the length of the flat part of the opening, the spacing between opening and the number of sinusoidal opening along the web of beam. In the optimization process, among stochastic search method, harmoniy search (HS) and particle Swarm (PS) algorithms are used in order to find minimum weight of the design problem. The design examples indicate that the HS method can achieve a minimum weight more efficiently and quickly in the optimum design of structures. Then, the ultimate load carrying capacities of optimally designed steel Angelina" beams are performed under the action of same concentrated loadings in a self reacting frame. The tests have been carried out on six full-scale non-composite cellular beams. The first two experiments on NPI_200 section beams have failed because of lateral torsional buckling due to a lack of lateral support. The results obtained from experimental tests on NPI_240 and NPI_300 section beams, on the other hand, demonstrate that in addition to web buckling, vierendeel bending has occurred on all of the four beams.

\section{Acknowledgement}

This paper is partially supported by the Scientific Research Project Cordination Units of Akdeniz University Research Funding (FBA-2015-284) and also partially supported by the Scientific Research Project Cordination Units of Karamanoğlu Mehmetbey University Research Funding (BAP-13-M15) which are gratefully acknowledge.

\section{References}

1. Kirkpatrick, S., Gerlatt, CD., Vecchi, MP. Optimization by Simulated Annealing. Science 1983; $220: 671$ - 680.

2. Glover, F. Tabu Search - Part I. ORSA Journal on Computing 1989; 1(3): 190 - 206. Goldberg DE. Genetic Algorithms in Search, Optimization and Machine Learning, Addison - Wesley Publishing. 1989.

3. Pezeshk S., Camp CV. State of the Art on the Use of Genetic Algorithms in Design of Steel Structures. Recent Advances in Optimal Structural Design 2002; 55 - 80.

4. Coello C. AC. Theoretical and numerical constraint - handling techniques used with evolutionary algorithms: a survey of the state of the art. Computer Methods in Applied Mechanics and Engineering 2002; 191: 1245 - 1287.

5. Dorigo, M. and Stützle, T. Ant Colony Optimization, A Bradford Book, Massachusetts Institute of Technology. 2004.

6. Dreo, J., Petrowski, A., Siarry, P. and Taillard, E. Meta - Heuristics for Hard Optimization, Springer - Verlag, Berlin, Heidelberg. 2006.

7. Lee, K.S. and Geem, ZW.. A New Structural Optimization Method Based on Harmony Search Algorithm. J. Computers and Structures 2004; 82: $781-798$. 
8. Perez, RE, Behdinan, K.. Particle Swarm Approach for Structural Design Optimization. Computers and Structures 2007; 85: 1579 - 1588.

9. British Standards, BS - 5950, 1990. Structural Use of Steelworks in Building. Part 1. Code of Practice for Design in Simple and Continuous construction, hot rolled sections, British Standard Institution, U.K., London.

10. P.R. Knowles. Design of Castellated beams. The Steel Construction Institute, 1985

11. J.K. Ward, Design of composite and non-composite cellular beams. The Steel Construction Institute Publication, 1990 